\title{
Erratum
}

\section{Chemistry of Lactam-Derived Vinyl Phosphates: Stereoselective Synthesis of (+)-Fagomine}

Laura Bartali, Dina Scarpi, Antonio Guarna, Cristina Prandi, Ernesto G. Occhiato* Synlett 2009, 913.

The authors would like to correct the text about the hydroboration-oxidation of compound $\mathbf{1 4}$ as follows:

We were delighted to observe that both steps proceeded smoothly and that the bulky 4-silyloxy group, which in $\mathbf{1 4}$ is axially oriented to remove the $\mathrm{A}^{(1,2)}$-strain with 3-H (Scheme 3), effectively directed the hydroboration to the opposite face, providing, after oxidation and chromatographic separation of the 13:1 diastereomeric mixture, compound $\mathbf{1 5}$ as a single isomer. ${ }^{19,20}$ Interestingly, the stereoselectivity in the addition of borane to $\mathbf{1 4}$ was slightly lower than that observed in the hydrogenation of $\mathbf{1 2}$ for the synthesis of 4-hydroxypipecolic acid. ${ }^{4}$ 